University of Nebraska - Lincoln

DigitalCommons@University of Nebraska - Lincoln

To Improve the Academy

Professional and Organizational Development Network in Higher Education

1994

Deepening and Broadening the Dialogue About Teaching

James R. Davis

Follow this and additional works at: https://digitalcommons.unl.edu/podimproveacad

Part of the Higher Education Administration Commons

Davis, James R., "Deepening and Broadening the Dialogue About Teaching" (1994). To Improve the Academy. 306.

https://digitalcommons.unl.edu/podimproveacad/306

This Article is brought to you for free and open access by the Professional and Organizational Development Network in Higher Education at DigitalCommons@University of Nebraska - Lincoln. It has been accepted for inclusion in To Improve the Academy by an authorized administrator of DigitalCommons@University of Nebraska - Lincoln. 


\section{Deepening and Broadening the Dialogue About Teaching}

\section{James R. Davis}

University of Denver

Although there has been a resurgence of interest in college teaching in recent years, it is important to deepen and broaden that interest. The dialogue can be deepened by reflecting more on learning, particularly the fundamental learning paradigms which provide the basis for alternative teaching strategies: training and coaching, lecturing and explaining, inquiry and discovery, and groups and teams. The dialogue can be broadened by reconnecting the discussion to major issues in curriculum planning and assessment.

For those who work in faculty development and particularly for those who have done so over many years, it is gratifying to see a renewed interest in teaching and the elevation of its importance. In Ernest Boyer's Scholarship Reconsidered (1990), the best-selling publication of the Carnegie Foundation for the Advancement of Teaching, teaching is no longer thought of as an activity to be placed over against research, but is conceptualized as one of the forms of scholarship. Faculty developers, bearing a variety of titles and playing a wide range of roles, are fully engaged in an ongoing dialogue with those who seek their help in the continuous improvement of teaching.

Unfortunately, the dialogue about teaching is too often superficial, focusing on techniques and remedies that lack grounding in solid theory. To deepen the dialogue about teaching, it is valuable to step back from teaching and ask: What is known about learning? The answer is "very much," and there is not just one theory but many. The 
theories, which often appear in educational psychology textbooks oddly detached from the real-world tasks of the classroom, are nonetheless valuable and a primary resource for anyone who wants to deepen the dialogue about teaching.

It is useful to think of what is known about learning in terms of somewhat separate and distinct paradigms, ways of looking at the world of learning. One might, of course, derive any number of categories and configurations for thinking about learning, but over the years I have settled on five that are separate and different enough to warrant the designation "paradigm." For each of these paradigms I have created a corresponding name for a "teaching strategy" based on that paradigm. The strategies and paradigms are as follows:

\section{STRATEGY}

Training and Coaching

Developing basic and advanced skills by using clear objectives, breaking instruction into steps, and reinforcing progress

\section{Lecturing and Explaining}

Conveying information, explaining concepts, theories, and ideas so that they can be understood and remembered

\section{Inquiry and Discovery}

Stimulating critical and creative thinking, problem-solving, and reasoning

\section{Groups and Teams}

Facilitating learning through group activities and team projects

\section{Experience and Reflection}

Helping students to reflect on their experience in work, service, or travel settings

\section{PARADIGM}

\section{Behavioral Psychology}

Based on the findings of behavioral psychology, particularly operant conditioning

Cognitive Psychology

Based on the findings of cognitive psychology about attention, information processing and memory

\section{Psychology of Thinking}

Based on aspects of cognitive psychology and philosophy related to thinking processes

\section{Group Communication Theory}

Based on the research from speech communication on-task and process behavior in groups

\section{Holistic Learning}

Based on brain research and holistic learning theory plus counseling psychology principles 
The training and coaching strategy is based on behavioral learning theory, the familiar and longstanding idea of operant conditioning growing out of the work of Watson (1934), Thorndike (1921), and B.F. Skinner (1969). The idea is simple enough: a response (in this case the student's behavior) will be repeated or not repeated, depending on the consequences to that response. Although often discounted by faculty who have "had enough" of behaviorism, it is still an important - perhaps even fundamental - paradigm for the dialogue about teaching. Out of it comes the important idea of shaping guiding students in successive approximations (small steps) towards a desirable goal through the appropriate use of feedback. Most teaching that involves the development of skills - writing, basic math, music, foreign language, and almost all physical skills - can be made more effective and efficient through the careful employment of the behavioral paradigm. Furthermore, the basic exchange of communication between students and teacher in any classroom discussion is governed by behavioral principles. What the student says is both content and behavior, and the way the faculty member responds is feedback. The way the teacher responds will shape the nature and extent of future responses, and through modeling, will shape the responses of others. The behavioral paradigm is there working all the time, and good teachers are aware of how to use it.

Another paradigm is what has come to be called "cognitive psychology," and it provides a sound base for the lecturing and explaining strategy. In the late 1950s a group of psychologists who had grown unhappy with the "simplistic" explanations of the behaviorists wanted to know more about what goes on in people's heads when they attend to, process, and remember information. Breaking away from the behaviorist idea that one can only study external behaviors, they began to develop models of covert mental process through a series of clever experiments that enabled them to make inferences about these processes. The result today is a coherent paradigm used to describe attention, information processing, and memory (Sanford, 1985). For anyone who lectures - and most college teachers do - it is important to understand what goes on in the heads of the students who are trying to pay attention to, understand, and remember the information that is being sent their way. Some of 
the useful findings are as follows: We have a limited capacity for attention, but we are good at focusing if we are told what is important. We tend to look for the general features of new information and relate that to information we already have, and the ease with which we do that depends on our previous experience, the schema we already have in place, and the "cognitive complexity" of what we are trying to comprehend. We remember almost nothing unless we convert it into long-term memory through some special storage processes known as mnemonic devices. The dialogue about lecturing (the most frequently used and abused teaching strategy), surely needs to move beyond "presentation skills" to a deeper discussion of what happens when people attend to, process, and remember information.

Most college teachers hope that their students will learn to think, but they themselves, odd as this may seem, have not thought much about what thinking is or the conditions under which it takes place. Another group of cognitive psychologists, aided by philosophers and others with broad interests in "thinking skills," have studied these processes as still another way of learning. Interestingly, there are many types of thinking - critical, dialogical, creative - involving many different kinds of processes - induction, deduction, problem-solving, decision-making - that make different uses of language, ranging from positivistic to metaphorical (Beyer, 1987). When human beings try to think, it is not always a pretty process to watch; it is something akin to horses falling in the steeple chase. For example, we tend to make few rather than numerous hypotheses, and we tend to seek only evidence that confirms our hypotheses, rather than seeking appropriate disconfirming evidence as well. When we make bad decisions, we tend to perpetuate them, following them with more bad decisions, rather than cutting our losses. We get terribly confused about how we are using language, and if our cognitive resources get overtaxed, we simply quit. One thing that is known for sure about thinking is that it is learned through practice. If students are to learn to think, classrooms need to be arranged in such a way as to foster active thinking processes. This means providing a safe environment where students' ideas can be set forth, shared, and shaped under the critical guidance of a skilled mentor who knows how to think in a particular field of study. This is why the strategy is called "inquiry and discovery." 
People also learn as a result of their participation in groups. The literature on groups and teams, found mostly in the field of speech communication, provides still another paradigm of how people learn. This kind of learning involves not only ideas, but also what educators call the "affective domain," the realm of opinions, attitudes, and beliefs, sometimes referred to as feelings and values. The study of the intentional use of groups for learning grows out of the early work of Kurt Lewin and his associates who were involved in establishing the National Training Laboratory (Golembiewski and Blumberg, 1970), the work of Carl Rogers (1970) in group therapy, and the work of E.L. Moreno (Hare, 1976) in sociodrama. Those who have studied groups know that communication in groups takes place at both a task (the job to be done) level and a process (social needs) level, that members play specific roles in the group, that groups become (or fail to become) cohesive, and that groups go through stages over time. Groups tend to generate many more ideas than individuals, and there is usually more acceptance of outcomes when they are derived through a group process. Perhaps the most important finding is that people actually change as a result of their participation in groups, and that attitudes and values - known to be deeply rooted in our natural group affiliations - are most likely to change when they are reexamined through a group process (Goldberg \& Larson, 1975). Groups have their drawbacks - the tendency of certain members not to do their part (social loafing) and an inclination toward conformity (group think) - but for certain kinds of learning, groups provide the right communication mechanism to reach the heart and soul.

Not all learning takes place in classrooms. Increasingly today, faculty find themselves engaged as the mentors of students in servicelearning projects; cooperative education work experience; overseas travel, study or service; and internships and field studies. All of this has come to be referred to as experience-based learning and involves still another learning paradigm. Do people learn from experience? Most do and, alas, some never seem to; but in educational settings it is important to understand what experience-based learning is and how it can be enhanced through a systematic reflection process. A paradigm to support the holistic learning that undergirds experience-based learning has emerged more recently and grows out of new research on 
the brain (Hart, 1983). Like the rest of the human body, the brain has evolved, and the stages of that evolution are recapitulated in the development of the human embryo, where the later cerebral cortex is only slowly added to an earlier "mammalian" and still earlier "reptilian" brain, three parts that, in adulthood, function in uneasy tension. What is most interesting about this brain is not so much its power to reason - which we have seen does not come naturally to the species - but its ability to take in, process, and make meaning of experience.

Through a process known as "encephalization," the species came to develop an unusually large cerebral cortex relative to body size; so humans can be thought of as "brain freaks" just as giraffes are "neck freaks" and elephants are "nose freaks." The purpose of this encephalization, it is believed, is for language; and what language is for, contrary to widespread belief, is not so much communication as the interpretation of experience. Humans are equipped with a highly sophisticated apparatus for seeing, hearing, and interpreting what goes on around them, as their key survival mechanism. Learning, so it is argued by holistic theorists, arises naturally from experience; it sticks to us, like mud to our shoes. David Kolb (1984) describes it as a cyclical process of going out to concrete experience, engaging in reflective observation, retreating to engage in abstract conceptualization, actively experimenting with new concepts, and returning to concrete experience to test those new concepts. Contrary to the model used by most academics, which might be characterized as "go apply what you have learned," experience-based learning seems to take place more through a process that Donald Schön (1983) calls "reflection-in-action." For faculty, the key role is that of reflector, and for the reflection part of experience-based learning one can turn to some of the less-complicated counseling theories to learn about how to help students reflect on their experience. Usually this involves helping them to identify problems and see missed opportunities, listening as they describe what is happening to them, and guiding them in developing preferred scenarios and taking steps to carry them out. Above all it is a process of helping them to make meaning through telling their story.

If deepening the dialogue about teaching is the goal, this deeper conversation will occur when we talk with faculty in increasingly sophisticated ways about learning, when we help them to distinguish 
among different kinds of learning, and encourage them to select teaching strategies based on learning paradigms. Of course this means that we ourselves need to be well-prepared to carry on that dialogue. For a much fuller discussion of each of the teaching strategies and learning paradigms, and for the references to support the ideas presented above, please see Better Teaching, More Learning: Strategies for Success in Postsecondary Settings (Davis, 1993). So much for deepening the dialogue.

What about broadening the dialogue? Improving teaching is only one variable in the effort to improve the overall quality of higher education. Most of the discussion of faculty development focuses on the improvement of teaching and often occurs in splendid isolation from the important issues of curriculum content and assessment of student learning outcomes. What appears to be developing are three separate literatures, three sets of professional associations (or subsidiary efforts within associations) which deal separately and sometimes exclusively with curriculum planning, improving teaching, and assessment. Much of this activity and the emerging literature is quite valuable, but it is compartmentalized and specialized.

For example, AAHE has sponsored extremely valuable annual conferences on assessment, and there is now a growing and very useful literature, including Alexander Astin's two volumes, Achieving Educational Excellence (1985) and Assessment for Excellence (1991), and Trudy Banta's new volume Making a Difference (1988). The Association of American Colleges leads the way in curriculum planning with the challenging three-volume set, The Challenge of Connecting Learning, Structure and Coherence: Reports from the Field (1991). There are valuable books, including Jerry Gaff's New Life for the College Curriculum (1991) and Robert Diamond's Designing and Improving Courses and Curricula in Higher Education (1989), as well as the useful journal, Liberal Education. Then there is the work of POD Network, along with many new books on improving teaching, including Stephen Brookfield's The Skillful Teacher (1990), Joseph Lowman's Mastering the Techniques of Teaching (1990), and the recently reissued version of the now classic Teaching Tips, by Wilbert McKeachie (1994). We now see emerging what appears to be three separate movements, not unlike the development of the separate 
academic disciplines, with all of the attendant hazards of conceptual isolation and provincialism. Ironically, these separate movements, with their own advocates, meetings, and scholars, mirror a similar kind of fragmentation in the disciplines and professions which many of us, in our own work, strive to overcome.

What most of us know, however, is that the problems we confront in improving the quality of education at local institutions seldom come in the tidy separate packages of curriculum, teaching, and assessment. These problems are closely connected and their solutions are interrelated. Even worse, when these activities are perceived as separate, efforts to improve are often superficial and ineffective. Much of the local resistance to assessment, for example, arises because faculty have trouble understanding how it is related to teaching or curriculum planning; they see it as a matter of compliance, rather than as a useful activity for gaining access to information that would be valuable in making decisions about how to modify the curriculum or improve teaching. Likewise, curriculum planning - resulting in genuinely creative new ideas - often takes place without much thought about what will be required to develop the kind of teaching needed to implement these ideas or the kinds of assessment needed to evaluate the effectiveness of the new curriculum. Similarly, teaching improvement programs are often undertaken quite apart from curriculum planning and assessment efforts, which on some campuses are even located in separate offices. Actually, these three activities are inseparable in practice.

Recently, the College of Law at the University of Denver redesigned a course entitled "The Lawyering Process." This course is required of all first-year students (about 350 day and evening) and is designed to introduce the students to the study of the three substantive areas of law (case law, legislation, and administrative law) and to the skills students will need to work in a law firm. To complement the large lecture format, students are divided into simulated law firms (20 students each), headed by a senior partner (a practicing attorney) and assisted by a junior partner (an upper division student assistant), a client, a writing consultant, and a librarian consultant. The firms are paired, plaintiff and defendant, around problem cases, which are used for developing practice skills throughout the course. 
Some of the faculty on the team left, and as others replaced them, they wanted to reexamine the course, and in particular to address student complaints. The course improvement process began with assessment activities, in which faculty began to articulate systematically the strengths and weaknesses of the course, and students conveyed through focus groups their perspectives on what they actually thought the course was about and how it was delivered. Interestingly, when students were asked to articulate their concerns, they could do so quite fluently; but when they were requested to state what the course was about and how it was organized, they stumbled. They didn't see the structure that the faculty thought was there. As course consultant, I could play the role of outside observer in asking questions that gave the faculty, also in attendance, a better idea of what improvements might be necessary.

The curriculum planning phase involved a rethinking of objectives, reordering of topics, and reconsideration of course materials, and testing and grading techniques. The "schematic" for the course, complete with schedules of activities for lectures and law firms, was completely revised, and the content themes of the law - case law, administrative law, and legislation - were made more visible.

Once the content of the course was agreed upon, interest shifted to teaching strategies and the training needed for this "cast of thousands" (more than 50 people) to make sure that the course was actually delivered as intended. Keeping everyone on the same page and in their assigned roles was not easy. Because the changes in the course were substantial, there was genuine interest on the part of the faculty to find out whether the changes made a difference - thus returning (full circle) to the assessment phase to find out how the course was received this year. Curriculum planning, the improvement of teaching, and assessment are and ought to be, as illustrated here, integrated processes.

The University of Denver is engaging in a new experiment to reunite these three activities. The name of the Center for Faculty Development has been changed to the Center for Academic Quality and Assessment of Student Learning, and the Director of the Center has been renamed "Special Assistant to the Provost." The Director's responsibility is to work with the faculty and administration broadly 
across the University on matters of curriculum planning, teaching improvement, and assessment. The colleges, schools, and departments are expected to own and shape their own activities, while the Director serves as a roving consultant, which the University provides (free) to these units, assisting them, wherever possible, in enhancing the quality of what they do to make it their best. Each unit establishes planning committees, faculty development committees, and assessment activities appropriate to their units. Sometimes the Director is invited to make brief presentations, sit with committees, assist curriculum or self-study committees, or, as in the case of the "Lawyering Process," help redesign an important course.

If it is true that we need to broaden as well as deepen the dialogue about teaching, then there are some interesting implications and opportunities for the POD Network. Certainly we need to continue to serve as a valuable forum for discussing organizational techniques for effective faculty development while seeking ways to talk more frequently and more seriously about what learning actually is. In doing this, we may also want to reach out laterally to initiate (again, more frequently and more seriously) discussions of the content of the curriculum and the assessment of student learning. Leaving the curriculum solely in the hands of disciplinary specialists, without benefit of informed reflection on the curricular planning process, is dangerous; it is perhaps even more dangerous to leave assessment in the hands of measurement specialists who may not appreciate, as much as we might wish, the complexities of the instructional process and the intricacies of the curriculum. In doing all of this POD will surely want to maintain its focus on the development of faculty, in the many ways that faculty develop through their careers but in the context of these broader movements with which there can be profitable dialogue.

What we all value ultimately, as members of the POD Network, is the continuous improvement of the quality of education provided for students. Surely this means continuing to work with faculty through the myriad of organizational techniques available to us; but it also means finding ways to deepen and broaden the dialogue about teaching, tying our efforts more directly to learning paradigms and connecting what we do, more consciously, to parallel movements to improve curriculum planning and assessment. 


\section{References}

Association of American Colleges. (1991). The challenge of connecting learning, structure and coherence: Reports from the field. Washington, D.C.: Association of American Colleges.

Astin, A. (1985). Achieving educational excellence: $A$ critical assessment of priorities and practices in higher education. San Francisco, CA: Jossey-Bass.

Astin, A. (1991). Assessment for excellence. Phoenix, AZ: The American Council on Education and Oryx Press.

Banta, T. (1988). Implementing outcomes assessment: Promise and perils. San Francisco, CA: Jossey-Bass.

Beyer, B. (1987). Practical strategies for the teaching of thinking. Boston: Allyn \& Bacon.

Boyer, E. (1990). Scholarship reconsidered. Princeton, NJ: The Carnegie Foundation for the Advancement of Teaching.

Brookfield, S. (1990). The skillful teacher. San Francisco, CA: Jossey-Bass.

Davis, J. (1993). Better teaching, more learning: Strategies for success in postsecondary settings. Phoenix, AZ: The American Council on Education and Oryx Press.

Diamond, R. (1989). Designing and improving courses and curricula in higher education: A systematic approach. San Francisco, CA: Jossey-Bass.

Gaff, J. (1991). New life for the college curriculum. San Francisco, CA: Jossey-Bass.

Goldberg, A., and Larson, C. (1975). Group communication. Englewood Cliffs, NJ: Prentice-Hall.

Golembiewski, R., and Blumberg, A. (1970). Sensitivity training and the laboratory approach. Itasca, IL: Peacock Publishers.

Hare, P. (1976). Handbook of small group research. New York: Free Press.

Hart, L. (1983). Human brain and human learning. New York: Longman.

Kolb, D. (1984). Experiential learning. Englewood Cliffs, NJ: Prentice-Hall.

Lowman, J. (1990). Mastering the techniques of teaching. San Francisco, CA: Jossey-Bass.

McKeachie, W. (1994). Teaching tips (9th ed.), Lexington, KY: Heath.

Rogers, C. (1970). On encounter groups. New York: Harper \& Row.

Sanford, A. (1985). Cognition and cognitive psychology. New York: Basic Books.

Schön, D. (1983). The reflective practitioner. New York: Basic Books.

Skinner, B. F. (1969). The contingencies of reinforcement. New York: Appleton-CenturyCrofts.

Thorndike, E. L. (1921). The psychology of learning. New York: Teacher's College Press.

Watson, J. B. (1934). Behaviorism. New York: The People's Publishing Institute. 